\title{
Is There a Correlation between Body Weight and Awareness of Healthy Life Style Components in Children?
}

\author{
Asma Deeb ${ }^{1 *}$, Shaker Suliman1, Mary Tomy ${ }^{1}$, Hana Yousef ${ }^{1}$, Layla Abdel Rahman'1, \\ Shifa Saleh" ${ }^{2}$, Samia Mahmoud $^{3}$, Mariette Akle ${ }^{4}$, Nico Nagelkerke ${ }^{5}$ \\ ${ }^{1}$ Paediatric Endocrinology Department, Mafraq Hospital, Abu Dhabi, United Arab Emirates \\ ${ }^{2}$ Paediatric Clinic, ADNOC Services, Abu Dhabi, United Arab Emirates \\ ${ }^{3}$ Abu Dhabi Police Medical Services, Abu Dhabi, United Arab Emirates \\ ${ }^{4}$ Psychology Services, Paediatric Department, Mafraq Hospital, Abu Dhabi, United Arab Emirates \\ ${ }^{5}$ Institute of Public Health, United Arab Emirates University, Al Ain, United Arab Emirates \\ Email: adeeb@mafraqhospital.ae
}

Received 22 February 2015; accepted 11 March 2015; published 16 March 2015

Copyright (C) 2015 by authors and Scientific Research Publishing Inc.

This work is licensed under the Creative Commons Attribution International License (CC BY).

http://creativecommons.org/licenses/by/4.0/

c) (i) Open Access

\begin{abstract}
Background: Incidence of obesity in children is increasing worldwide. Healthy eating and exercise are the major components of a healthy life style in the community. Objective: we aim to assess the knowledge of healthy eating and exercise in children of varying weight and to explore the correlation between knowledge and bodyweight. Method: School children are invited to fill in a 2 questions quiz about healthy life style. BMI is calculated and children are classified into obese, overweight, normal and underweight. Answers are scored and results compared for different categories of the BMI. Results: 445 children participated. Age range (mean) was 7 - 13 (10) years. 67 were obese, 59 overweight, 237 normal weight and 34 were underweight. In the food question, $22 \%, 20 \%, 23 \% 15 \%$ of obese, overweight, underweight and normal weight children respectively gave wrong answers compared to $17.5 \%, 15 \%$ and $14.7 \%, 13.3 \%$ for the exercise question. Neither of the results was statistically significant. Boys are more knowledgeable about exercise than girls $(P=0.03)$. Conclusion: There is no difference in the level of knowledge about healthy eating and exercise among children with varying body weights. Tackling children behavior and attitude towards food and exercise is as important as improving their knowledge.
\end{abstract}

\section{Keywords}

Obesity, Exercise, Diet, Children, Overweight

\footnotetext{
${ }^{*}$ Corresponding author.
}

How to cite this paper: Deeb, A., Suliman, S., Tomy, M., Yousef, H., Rahman, L.A., Saleh, S., Mahmoud, S., Akle, M. and Nagelkerke, N. (2015) Is There a Correlation between Body Weight and Awareness of Healthy Life Style Components in Children? Open Journal of Pediatrics, 5, 49-55. http://dx.doi.org/10.4236/ojped.2015.51010 


\section{Introduction}

The incidence of obesity in children is developing into a major pandemic. Over the past 30 years, obesity has doubled in children and tripled in adolescents [1]. In 1980, the percentage of obese children aged between 6 and 11 years in the USA was 7\%. However, this percentage increased to $18 \%$ in 2010. Adolescents aged between 12 and 19 showed a similar increase in obesity with an overall percentage increasing from 5\% to 18\% [1]. Similarly, in the United Arab Emirates (UAE), the prevalence of childhood overweight and obesity reached up to 25\% [2].

Overweight and obesity are defined as having excess body weight for a particular height [3]. They result from caloric imbalance between calories consumed and those expended [4]. Healthy eating is crucial to reduce the risk of many pathologies including cardiovascular disease, cancer, stroke, and diabetes [5]. In childhood, healthy eating is particularly important for growth and development and the prevention of lifelong metabolic disorders. In a study by Sinha et al., up to $25 \%$ of obese children and adolescents were found to have glucose intolerance and $4 \%$ had type 2 diabetes [6]. In a school-based study at the UAE, it was found that $13 \%$ of boys had the metabolic syndrome, a percentage that has gone up to $59 \%$ in obese boys [7]. In the same population, high blood pressure is found to be significantly higher in obese adolescents [8].

The ideal recommended diet is that rich in fruits and vegetables, whole grains and low fat dairy products for children above 2 years of age. It is highly recommended that people reduce the intake of saturated and transfatty acids, cholesterol, sodium, added sugar and refined grains [5]. Secular trends in dietary intake show that most children and adolescents are not following the recommended guidelines [9] [10]. In the UAE, high proportion of children and adolescents fail to meet the dietary recommendation [11]. In this country, dietary habits in the form of skipping breakfast and eating fast food have been identified as major cause of obesity in adolescents [12]. Regular exercise is of crucial importance to children and adolescents. It improves strength and body built and has an impact on development of healthy bones and muscles. Equally important is that exercise helps to control weight. It is recommended that children aged 6 - 17 years participate in a minimum of 60 minutes of exercise daily [13]. In a survey undertaken in 2011, it was found that less than a third of school students achieved the recommended exercise guidelines and only 31\% attended daily physical education class [14]. Although some school programs appear effective in helping children and adolescents in acquiring healthy life style, lack of compliance to healthy diet and exercise outside school hours appear to enhance loss of benefits of these program resulting in failure of the final outcome of the school programs [15]. Accordingly, continuity of the program principles outside school hours is crucial for the success of such programs.

Many education programs are organized throughout the world targeting school children. Education schemes and campaigns are available internationally with varying degrees of success. Healthy eating and sufficient exercise are the two major components of these healthy life style programs in the community. Educating children about the food quality and importance of exercise constitute the main objectives of many obesity programs/ campaigns. It has not been documented that obese or overweight children have less knowledge of healthy food and exercise compared to their peers of normal or low weight children. Moreover, it is assumed that obesity and overweight in children result from a lack of knowledge on the role of nutrition and exercise.

Objectives: We aim to assess if the level of knowledge correlates with the body weight in children, and to examine the hypothesis that simple lack of healthy eating and exercise are more prevalent in obese and overweight children than in their normal weight peers.

\section{Materials and Methods}

School children of both sexes at ages between 7 and 13 (grades between 3 and 9) are invited to participate in the study. The study took place in 2 venues; one is our hospital during visits for health education campaigns and the other is the children's schools which our team of nurses visited during health education days. The study period was between September and December 2013. The study was explained to the children attending the educational campaigns and activity days by our team of specialist nurses and they were invited to participate. Children who wished to participate came forward to answer the quiz at allocated stands manned by a team of specialist nurses. Enrolled children gave verbal consent to participate and the quiz questions were explained to them individually by the specialist nurses. The study was approved by the local Mafraq hospital Ethics Committee.

The study quiz consisted of 2 multiple choice questions. In the first question, various food items (chocolate, dairy products, burgers, pizza, fruits, vegetables and crisps) are displayed and children are asked to tick the healthy options. Similarly, forms of entertaining activity (running, swimming, watching TV, playing a video 
game and running) are listed and a tick is requested to be put on the healthy form of the activity. The choice of the food items in the first question was based on commonly-available food items in the area. Similarly, exercise modalities were chosen based on well-known forms of exercise or entertainment practiced in the region.

Children are explained the quiz verbally by a team of 4 specialist nurses and given time to complete it themselves. Height and weight of children are taken on the day by the study team and BMI calculated. BMI is plotted on the BMI centile chart. Children whose BMI exceed the $97^{\text {th }}$ centile and the $85^{\text {th }}$ centile are classified as obese or overweight respectively. Children with BMI under the $3^{\text {rd }}$ centile are classified as underweight and those between the $3^{\text {rd }}$ and $85^{\text {th }}$ centile as normal weight as per the CDC charts.

The quiz is given a total score of 10 with each correct item given one point ( 5 for the diet question and 5 for the exercise question). Each participant was scored individually and scores were ranked under the BMI category. The study was approved by the local Research \& Ethics committee.

\subsection{Quiz Validation}

Validity is ensured by individually explaining to children what the questions mean and how to answer them. To confirm validity further, the quiz was piloted in the pediatric clinic and was tested by patients and the clinic staff.

\subsection{Power Calculation}

Required sample size is calculated to be 300 children to demonstrate $80 \%$ power with a significance level of 5\%.

\subsection{Statistical Method}

The effect of BMI category (underweight, normal, overweight, obese) and sex on correctly answering the two questions were examined using standard cross-tabulation and the Chi-Square statistic. The association between the two answers was analyzed using Cross-tabulation, Kappa statistic and the Odds ratio. The effect of BMI category and sex were also analyzed using logistic regression with either BMI class as a continuous or a binary (normal vs other categories) co-variable. The total number of correct answers was analyzed using ordinal, proportional odds, regression. SPSS v.22 was used for all analyses.

\section{Results}

445 children participated by completing the quiz. 50 entries were excluded due to incomplete information. Data from 395 children (202 females) were thus analyzed. Children age range (mean) was 7 - 13 (10) years. 67 children (17\%) were obese, 59 (15\%) overweight, 237 (60\%) normal weight and 34 (8\%) were underweight. In the food question, 22\%, 20\%, 23\% of obese, overweight and underweight respectively gave wrong answers compared to $15 \%$ of normal-weight children (Table 1). For the exercise question, $17.5 \%, 15 \%$ and $14.7 \%$ of underweight, overweight and obese children gave wrong answers compared to $13.3 \%$ of the normal weight (Table 2). Although lower numbers of normal weight children gave wrong answers for both food and exercise questions, none of these differences were statistically-significant at the 5\% significance level. Significance was neither seen when analyzed for trend (correlation with increasing BMI), with a standard Chi-Square test (i.e. treating BMI classes as categorical), nor when normal BMIs were compared to others (i.e. underweight, overweight/obese). These results were confirmed using multivariate logistic regression with sex and BMI class as co-variables. This analysis however showed that males, more frequently, got exercise questions right than girls (adjusted OR 1.9; 95\% CI: $1.1-3.5 ; \mathrm{p}=0.03$, adjusting for BMI class as a categorical variable). Ordinal regression with the number of correct answers as outcome variable did not show a statistically significant association with either BMI class or sex. There was a strong association between correctness for the food and exercise questions in females (OR 18.4; 95\% CI: 7.5 - 44.9) but less so in males (OR 2.2; 95\% CI 0.82 - 5.9).

\section{Discussion}

Food intake and exercise are the two major components of maintaining body weight. Educating children about the food quality and importance of exercise constitute the main objectives of many obesity programs/campaigns. Knowledge about healthy diet and exercise might be available to children and parents but the knowledge in its own might not be sufficient. In our study, we found that children of varying body weight have an approximately 
Table 1. Summary of answers given by participants for the "Food" question based on BMI class and sex cross-tabulation.

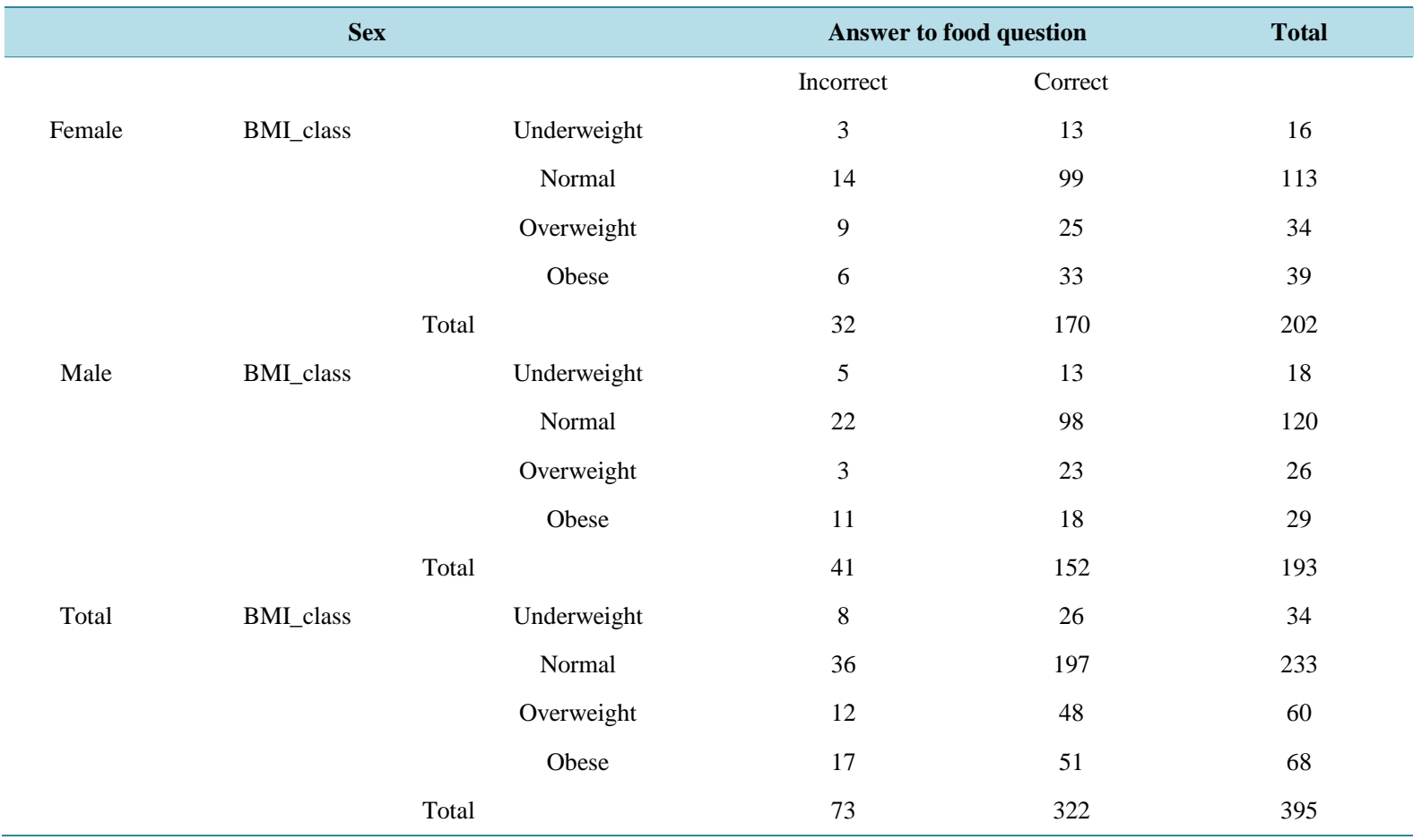

Table 2. Summary of answers given by participants for the "Exercise" question based on BMI class and sex cross-tabulation.

\begin{tabular}{|c|c|c|c|c|c|}
\hline \multicolumn{3}{|c|}{ Sex } & \multicolumn{2}{|c|}{ Answer to Exercise question } & \multirow[t]{2}{*}{ Tota } \\
\hline & & & Incorrect & Correct & \\
\hline \multirow[t]{5}{*}{ Female } & BMI_class & Underweight & 4 & 12 & 16 \\
\hline & & Normal & 19 & 94 & 113 \\
\hline & & Overweight & 5 & 29 & 34 \\
\hline & & Obese & 9 & 30 & 39 \\
\hline & \multicolumn{2}{|c|}{ Total } & 37 & 165 & 202 \\
\hline \multirow[t]{6}{*}{ Male } & BMI_class & Underweight & 2 & 16 & 18 \\
\hline & & Normal & 12 & 108 & 120 \\
\hline & & Overweight & 4 & 22 & 26 \\
\hline & & Obese & 2 & 27 & 29 \\
\hline & \multicolumn{2}{|c|}{ Total } & 20 & 173 & 193 \\
\hline & \multicolumn{5}{|c|}{ No. of males answered t exercise question correctly (OR 1.9; 95\% CI: $1.1-3.5 ; p=0.03$ ) } \\
\hline \multirow[t]{5}{*}{ Total } & BMI_class & Underweight & 6 & 28 & 34 \\
\hline & & Normal & 31 & 202 & 233 \\
\hline & & Overweight & 9 & 51 & 60 \\
\hline & & Obese & 11 & 57 & 68 \\
\hline & \multicolumn{2}{|c|}{ Total } & 57 & 338 & 395 \\
\hline
\end{tabular}

similar basic knowledge of healthy diet and exercise. This observation proves that for a child to passively know what is good for health is not necessarily enough to induce an active participation in his/her own healthy lifestyle schedule. In a study by Lindelof et al., it is shown that obese adolescents are aware that they have unheal- 
thy eating habits and they have the intention and desire to consume a healthier diet to reduce their weight. However, other underlying issues interfere with their plans. These issues are mainly related to self-blame and lack of parental support [16].

Parents must have the appropriate education of the healthy weight for their children. In a recent study in the UAE, parents' insight to their children obesity was a major concern in prevention and management of obesity [17]. Having the knowledge but not applying it in real life remains the main issue. Behavior changes strategies are crucial in implementing any improvement in the life style. A study by Hart et al. uncovered added barriers to obesity management. These are mainly in the form of unrealistic expectation and high optimistic bias. Accordingly, realistic outcome of intervention measures and empowering patient were concluded to be important targets in obesity-related health programs [18].

In various areas of the world where obesity is common, children are well educated about healthy eating and exercise. In 3 schools surveys in France, children could list examples of healthy foods competently. However, they expressed that their preferred foods are those rich in sugar and/or fat. In addition, a substantial number of those children practiced no exercise outside school hours [19]. In our group of children, we found that boys were more educated about the healthier forms of exercise than girls. This observation could be related to the cultural and social aspects in the UAE where boys are more encouraged and have more access to exercise than girls. In a study investigating travel to school, in Abu Dhabi, UAE, far fewer children are cycling or walking to school. On the contrary, the majority are being driven to school by car [20]. Absence of active travel culture in the community is seen as a significant contributory factor.

Maintaining appropriate weight remains to be a difficult task if unhealthy food supply remains accessible to children particularly if they are inactive. However, well-designed dietary education programs can be effective to help obese children and their parents to improve nutrition education and improve food habits and behavior [21].

For a successful dietary program, it needs to include measures to improve dietary behavior and not purely to be confined to increase level of knowledge. Saksvig et al. showed that such a program resulted in increase in dietary intention, preference and dietary self-efficacy [22]. Schools have a primary role in delivering such programs. They are ideal venue to promote healthy eating and their input is valuable in preventing and reducing this public health problem.

Linking education to behavior alteration is important. The child needs to be educated to understand how the quality of food and exercise help the body to remain healthy. Secondly, incorporating knowledge and adherence to the life style changes should be maintained. Although genetic and environmental factors play crucial role in the etiology of obesity, lack of education on the healthy life style approach and behavioral attitudes towards food remain to be important direct factors for obesity. Education campaigns around the world to increase awareness on the importance of adapting healthy life style are abundant. However, measures to link education to the proper behavior alteration towards eating pattern and exercise are not fully undertaken. We conclude that education alone is not the only solution to prevent obesity. Knowledge acquired by education needs to be integrated with beliefs and reflected on behavior to produce results. Provision of psychology service in centers dedicated to childhood obesity is valuable to empower children and motivate parents to prevent and manage obesity.

\section{Authors' Contribution}

Asma Deeb: Wrote the study proposal, was interviewed by Ethics committee, liaised subject interviews with schools and marketing department, wrote and submitted the manuscript.

\section{Acknowledgements}

We acknowledge Mafraq hospital marketing department for their role in arranging the educational events at the hospital and the nearby schools.

\section{Conflict of Interest}

No conflict of interest to report.

\section{References}

[1] Ogden, C.L., Carroll, M.D., Kit, B.K. and Flegal, K.M. (2012) Prevalence of Obesity and Trends in Body Mass Index 
among US Children and Adolescents 1999-2010. Journal of the American Medical Association, 307, 483-490. http://dx.doi.org/10.1001/jama.2012.40

[2] Malik, M. and Bakir, A. (2007) Prevalence of Overweight and Obesity among Children in the United Arab Emirates. Obesity Reviews, 8, 15-20. http://dx.doi.org/10.1111/j.1467-789X.2006.00290.x

[3] Krebs, N.F., Himes, J.H., Jacobson, D., Nicklas, T.A., Guilday, P. and Styne, D. (2007) Assessment of Child and Adolescent Overweight and Obesity. Pediatrics, 120, S193-S228. http://dx.doi.org/10.1542/peds.2007-2329D

[4] Daniels, S.R., Arnett, D.K., Eckel, R.H., et al. (2005) Overweight in Children and Adolescents: Pathophysiology, Consequences, Prevention, and Treatment. Circulation, 111, 1999-2002. http://dx.doi.org/10.1161/01.CIR.0000161369.71722.10

[5] (2010) Report of the Dietary Guidelines Advisory Committee on the Dietary Guidelines for Americans. U.S. Department of Agriculture, Department of Health and Human Services 2010, 7th Edition, US Government Printing Office, Washington, DC.

[6] Sinha, R., Fisch, G., Teague, B., et al. (2002) Prevalence of Impaired Glucose Tolerance among Children and Adolescents with Marked Obesity. New England Journal of Medicine, 346, 802-810. http://dx.doi.org/10.1056/NEJMoa012578

[7] Mehairi, A.E., Khouri, A.A., Naqbi, M.M., et al. (2013) Metabolic Syndrome among Emirati Adolescents: A SchoolBased Study. PLoS, 8, e56159. http://dx.doi.org/10.1371/journal.pone.0056159

[8] Al Junaibi, A., Abdulle, A., Sabri, S., Hag-Ali, M. and Nagelkerke, N. (2013) The Prevalence and Potential Determinants of Obesity among School Children and Adolescents in Abu Dhabi, United Arab Emirates. International Journal of Obesity, 37, 68-74. http://dx.doi.org/10.1038/ijo.2012.131

[9] Briefel, R.R. and Johnson, C.L. (2004) Secular Trends in Dietary Intake in the United States. Annual Review of Nutrition, 24, 401-431. http://dx.doi.org/10.1146/annurev.nutr.23.011702.073349

[10] Reedy, J. and Krebs-Smith, S.M. (2010) Dietary Sources of Energy, Solid Fats, and Added Sugars among Children and Adolescents in the United States. Journal of the American Dietetic Association, 110, 1477-1484. http://dx.doi.org/10.1016/i.jada.2010.07.010

[11] Ali, H.I., Ng, S.W., Zaghloul, S., Harrison, G.G., Qazaq, H.S., El Sadig, M. and Yeatts, K. (2013) High Proportion of 6 to 18-Year-Old Children and Adolescents in the United Arab Emirates Are Not Meeting Dietary Recommendations. Nutrition Research, 33, 447-456. http://dx.doi.org/10.1016/j.nutres.2013.03.008

[12] bin Gazaal, A.A., Musaiger, A.O. and D’Souza, R. (2009) Dietary Habits Associated with Obesity among Adolescents in Dubai, United Arab Emirates. Nutrición Hospitalaria, 24, 437-444.

[13] US Department of Health and Human Services (2008) Physical Activity Guidelines Advisory Committee Report. US Department of Health and Human Services, Washington DC.

[14] Eaton, D.K., Kann, L., Kinchen, S., Shanklin, S., Flint, K.H., Hawkins, J., et al. (2012) Youth Risk Behavior Surveillance, United States, 2011. Morbidity and Mortality Weekly Report, 61, 1-162.

[15] Donnelly, J.E., Jacobsen, D.T., Whatley, J.E., Hill, J.O., Swift, L.L., Cherrington, A., et al. (1996) Nutrition and Physical Activity Program to Attenuate Obesity and Promote Physical and Metabolic Fitness in Elementary School Children. Obesity Research, 4, 229-243. http://dx.doi.org/10.1002/j.1550-8528.1996.tb00541.x

[16] Lindelof, A., Nielsen, C.V. and Pederen, B.D. (2010) Obesity Treatment, More than Food and Exercise: A Qualitative Study Exploring Obese Adolescents' and Their Parents' Views on the Former's Obesity. International Journal of Qualitative Studies on Health and Well-Being, 5, 1-11.

[17] Aljunaibi, A., Abdulle, A. and Nagelkerke, N. (2013) Parental Weight Perceptions: A Cause for Concern in the Prevention and Management of Childhood Obesity in the United Arab Emirates. PLoS ONE, 8, e59923. http://dx.doi.org/10.1371/journal.pone.0059923

[18] Hart, K.H., Herriot, A., Bishop, J.A. and Truby, H. (2003) Promoting Healthy Diet and Exercise Patterns amongst Primary School Children: A Qualitative Investigation of Parental Perspectives. Journal of Human Nutrition and Dietetics, 16, 89-96. http://dx.doi.org/10.1046/j.1365-277X.2003.00429.x

[19] Bellisle, F. and Rolland-Cachera, M.F., Kellogg Scientific Advisory Committee (2007) Three Consecutive (1993, 1995, 1997) Surveys of Food Intake, Nutritional Attitudes and Knowledge, and Lifestyle in 1000 French Children, Aged 9-11 Years. Journal of Human Nutrition and Dietetics, 20, 241-251. http://dx.doi.org/10.1111/j.1365-277X.2007.00773.X

[20] Badri, M.A., Ustadi, A.M., Pierson, L. and Al Dramaki, M. (2012) Mode of Travel and the Decision to Allow Children to Walk or Bike to Schools, the Abu Dhabi Experience. Open Journal of Preventive Medicine, 2, 514-527. http://dx.doi.org/10.4236/ojpm.2012.24071

[21] Shin, E.K., Lee, H.S. and Lee, Y.K. (2004) Effect of Nutrition Education Program in Obese Children and Their Parents (II): Focus on Nutrition Knowledge, Eating Behaviors, Food Habit and Nutrient Intakes. Korean Journal of Community 
Nutrition, 9, 578-588.

[22] Saksvig, B.I., Gittelsohn, J., Harris, S.B., Hanely, A.J.G., Valente, T.W. and Zinman, B. (2005) A Pilot School-Based Healthy Eating and Physical Activity Intervention Improves Diet, Food Knowledge, and Self-Efficacy for Native Canadian Children. Journal of Nutrition, 135, 2392-2398. 